\title{
The influence of low-performing students' motivation on selecting courses from the perspective of the sport education model
}

\author{
Chun-Chieh $\mathrm{Kao}^{\mathrm{ABCD}}$, Yu-Jy Luo ${ }^{\mathrm{ABCDE}}$ \\ Office of Physical Education, Ming Chuan University, Taiwan
}

Authors' Contribution: A - Study design; B - Data collection; C - Statistical analysis; D - Manuscript Preparation; E - Funds Collection.

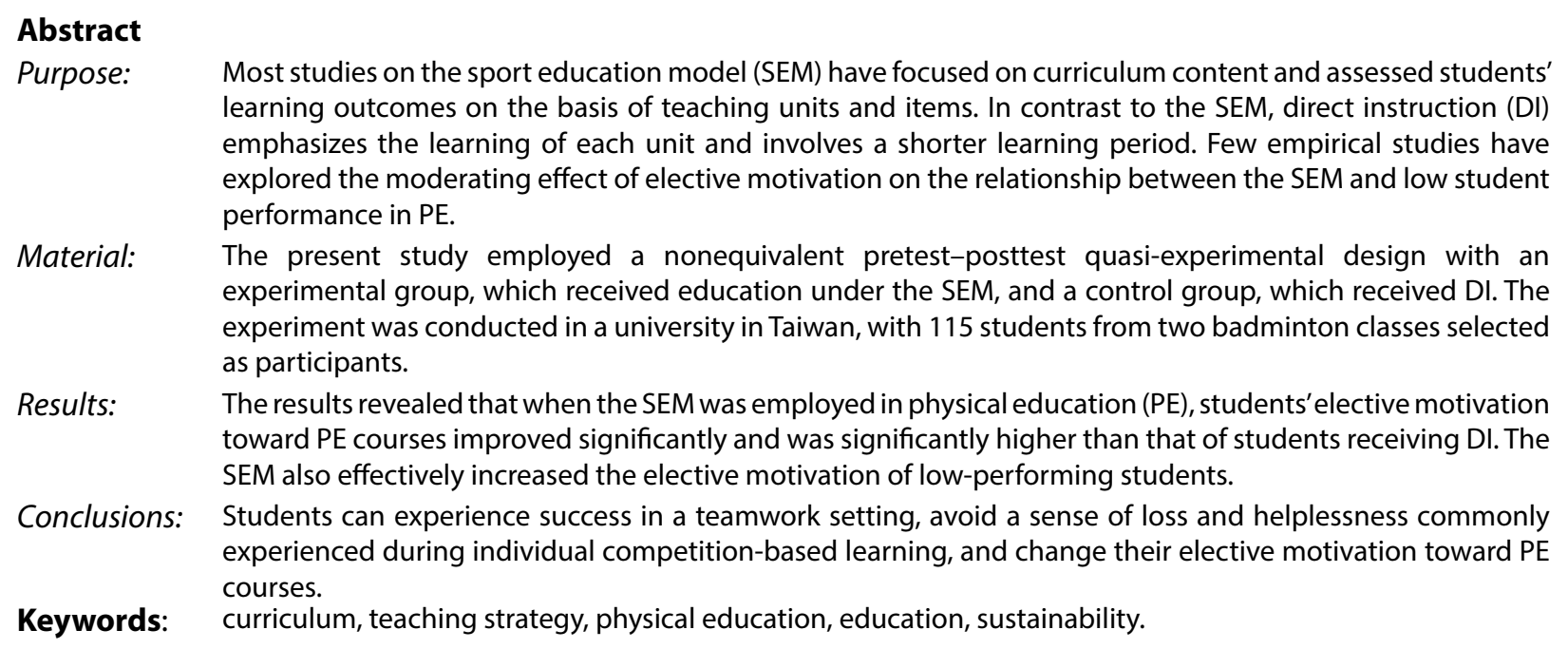

\section{Introduction}

Morris Chang, a fellow of the Industrial Technology Research Institute and the founder of Taiwan Semiconductor Manufacturing Company, asserted that top universities should focus on cultivating leadership skills in students. In addition to education related to professional disciplines and research training, the cultivation of talented leaders should entail providing instruction on various general education topics [1]. Physical education (PE) is an essential component of general education [2] because it not only encourages students to engage in mutual communication in an environment of trust but also allows them to participate in sports activities to enhance their teamwork ability, which is required for future workplace scenarios [3]. Accordingly, PE is crucial to the development of the social skills of students $[4,5]$. The importance of $\mathrm{PE}$ is attributable to its positive effect on students' adherence to a healthy lifestyle as well as their physical fitness [6].

In Taiwan, PE is a compulsory subject in school [3]. The characteristics of this type of education and scenarios it provides facilitate the positive development of adolescents [7]. However, not all students enjoy PE. When children enter adolescence, their learning motivation toward PE usually decreases [8,9], particularly for students with poor performance in such education [10]. Such students do not understand the subject, which then leads to their unwilling to learn [11]. Students who exhibit low learning performance learn slowly mainly because they are learning under an unfavorable cultural environment. Most schools in Taiwan do not offer remedial sessions for students with

\footnotetext{
(c) Chun-Chieh Kao, Yu-Jy Luo, 2019

doi:10.15561/20755279.2019.0601
}

low PE performance. Rather, schools merely observe the overall PE performance of all students in each homeroom class and overlook individuals with poor performance. Most studies on the sport education model (SEM) have focused on curriculum content and assessed students' learning outcomes on the basis of the teaching units and items. Further clarification is required to describe the relationship between the elective motivation of $\mathrm{PE}$ courses and teaching strategies and how this relationship affects students' learning outcomes and intention to enroll in PE classes. In addition, few empirical studies have explored the intervention effect of SEM on the elective motivation of low-performing students in PE; therefore, further research is required to investigate this topic and clarify the relationship between the SEM and students with low PE performance.

Theoretical background

Sports education model based on play theory: Since the promotion of the SEM in the 1908s in middle and elementary schools in Ohio, United States, this model has gradually replaced conventional PE curricula that involve diverse activities and become prevalent in New Zealand and Australia [12]. Siedentop posited that the SEM is based on play theory [13]. A sports activity can be viewed as a complex competition that is considered a systemically designed game. In such a game, students can improve their teamwork ability and adaptation to society, both of which are the goal of active participation in sports. Conventional $\mathrm{PE}$ is skill-oriented and isolates physical movements from a competition scenario [14]. Specifically, such education requires students to repeatedly practice basic movements and skills but does not reflect a real competition scenario. 
Consequently, students often do not experience the fun of participating in a sports game or learn to develop game strategies, causing their learning to become meaningless and neglecting the intended purpose of PE [13]. In summary, games play a critical role in PE and shows great value in this form of education. Specifically, employing games in PE can not only improve students' learning motivation but also replace conventional skill-based learning with competitive game scenarios that encourage students to engage in voluntary and effective learning.

The SEM is a curriculum and teaching model based on play theory and stems from the aim of promoting participation in public sports [13]. The six characteristics of the SEM are seasons, affiliation, formal competition, keeping records, festivity, and culminating events. Grouping in the SEM differs from that in conventional $\mathrm{PE}$ in that SEM grouping entails role-playing, which is a crucial socialization process. Role-playing allows students with poor skills to become involved in different sports team mechanisms and provides students with comprehensive sports experience [15, 16]. Compared with conventional PE practices, the use of the SEM can better imbue students with a passion for PE [17] and help them develop their athletic potential [18].

A study reported that the SEM provides a real, attractive, and festive learning environment [19]. Specifically, the SEM involves holding formal competitions between teams, which are highly attractive to students [20]. Even after the class is over, students tend to maintain a high level of interest in such competitions [21]. Therefore, game-based teaching improves students' participation in sports [22], learning motivation [17], and team cohesion [3], and encourages them to fulfil personal and social responsibilities [23]. Therefore, the SEM is considered a teaching strategy that attracts students' attention. Implementing the SEM provides learners with real sports experience, increase their participation rate, and exerts a positive effect on their learning outcomes, motivational needs, decision-making, and interpersonal interaction. By contrast, direct instruction (DI) emphasizes the learning of each unit and involves a shorter learning period. The content of such instruction mostly entails the repeated practice of skills and familiarization with certain movements. Sports knowledge and skills acquired from DI is relatively limited compared with those required in real competitions [15].

Self-determination theory and the elective motivation of low-performing students: Self-determination theory was proposed by [24]. It is a macro-level theory that concerns flexible human motivation and personality and facilitates understanding of human cognition, behavior, and emotion under general and specific scenarios. This theory posits that autonomous motivation, autonomous learning, and participation are the three basic psychological needs of students [25]. It emphasizes that a person's motivation includes intrinsic motivation, extrinsic motivation, and amotivation, the degree changes with the self-determination degree, and these changes will affect the individual's participation in an activity. In accordance with the Self-determination theory [24], even in the absence of external rewards, one will still choose to take physical education courses and be satisfied and feel happy in the classes, and thus promote the autonomous behaviour towards the next step and also enhances one's intrinsic motivation. This is also the benign behavior cycle pointed out by [26]. Therefore, when students perceive positive feelings of autonomy, competence, and relatedness, they will be positively influenced by their motives, that is, influence the type of motivation through psychological intermediaries, and then influence their behavioral outcomes. When individuals perceive that their internal control and behavior are determined by their free will, they tend to demonstrate higher levels of motivation to engage in self-determination [27].

The decision making factors when selecting physical education courses includes healthy and fitness, achievement assurance, personal relationship, teacher performance, facilities and equipment [28]. This indirectly echoes that the main benefits of the physical education do not only provide the development of sports skills, but also enhance the development of physical fitness [6], the cultivation of interpersonal relationships [3] and the affirmation of self-achievement [16]. However, students' motivations when choosing courses are sometimes affected by factors including the institute's venue and facilities, teachers' teaching methods, attitudes, and academic literacy, etc. The current physical education implemented in colleges and universities in Taiwan is grouped teaching based on students' interests. When the education is conducted based on students' interests, students' selection options, course selection motivations, willingness and factors of considerations should be made from students prospective. Thus, students' willingness to take the courses will be increased when they can get what they expected for physical education courses. In other words, under an effective physical education curriculum, students can be assisted by physical education teachers through the courses.

From a constructivist perspective, learning is not a replication or reproduction of knowledge and skills but an active meaning-making process that a learner actively engages in [29]. Low PE performance is attributable to a lack of attention during class, which causes students to experience difficulty receiving information and leads to inappropriate self-efficacy and expectations [10]. Some scholars have proposed that low PE performance is mainly due to low self-esteem [30]. In higher education, low-performing students require social support different from their counterpart with relatively high performance [31], and students' academic achievements can improve their learning motivation and provide them with selfconfidence [32]. This indicates that the highly autonomous motivation of individuals activates and guides their subsequent behaviors [33], and behavioral choices improve behavioral intention and engagement [34]. In the case of PE, a teaching environment shaped by the appropriate teaching methods of the instructor effectively affects students' learning motivation [35]. The teaching 
behavior of the instructor also exerts a substantial effect on students' self-determination, including their values and willingness to participate in class activities [36].

Equality in education opportunity has been a pertinent topic worldwide [37]. Several studies on low PE performance have indicated that students with unsatisfactory $\mathrm{PE}$ performance can gain real sports experience by participating in PE $[15,16]$; this improves their peer relationships and promotes peer imitation [21]. During social interactions in PE, low-performing students can receive support and avoid a sense of loss and helplessness that is commonly experienced during competition-based learning [10]. Therefore, effective teaching strategies can be adopted to help students with poor performance receive peer support and encouragement, thus encouraging them and ensuring their success in a group scenario [38]. The aforementioned assertions indicate that students with poor PE performance are most in need of close attention and intervention using suitable teaching strategies. Help should be provided to assist students in addressing their learning difficulties and alleviate their aversion to playing sports.

The current education system in Taiwan provides information, including that related to books, knowledge, and hands-on activities, that can be easily accessed using the Internet. However, only PE has an irreplaceable function, which merits the deliberation of education workers regarding how the content of PE curricula can be presented and how to effectively integrate theory with practice. Exploring the elective motivation of students entails further exploration of the education environment provided in class.

Research questions and hypotheses: According to the aforementioned assertions, this study was conducted to examine whether the SEM can be employed to provide a supportive PE learning environment for low-performing students and to explore the effect of such an environment on the elective motivation of students. Under the premise of a student-oriented teaching strategy, this study designed a teaching experiment to examine the SEM and its effect on improving students' PE performance, thereby attaining the ideal of homogenous educational benefits. The experimental results can also serve as a reference for subsequent research and education practice. Therefore, this study examined and identified solutions to the following questions: (1) the effect of the SEM on students' motivation to select PE courses, (2) the difference between students' motivation to select PE courses taught using DI and the SEM, and (3) the effect of the SEM on the motivation of low-performing students to select PE courses. According to the aforementioned factors and a literature review, this study inferred that the SEM can change students' motivation to select PE courses. Three hypotheses are proposed regarding the selection of PE courses:

H1: The SEM significantly improves the elective motivation of students.

H2: The elective motivation of students being educated using the SEM is significantly higher than that of students receiving DI.

H3: The elective motivation of low-performing students being educated using the SEM is significantly higher than that of low-performing students receiving DI.

\section{Materials and methods}

Participants: The experiment was performed in a university in Taiwan, where 115 students from two badminton classes were recruited as the participants. The experimental group comprised 59 students ( 32 men and 27 women; mean age: $21.42 \pm 0.75$ years). The control group comprised 56 students (29 men and 27 women; mean age: $21.38 \pm 0.73$ years). To reduce interference from irrelevant variables and extraneous variables, this study mainly recruited students who had not received SEM education or enrolled in any SEM course.

Research design: The present study employed the nonequivalent pretest-post-test quasi-experimental design with an experimental group, which received the SEM, and a control group, which received the DI. In consideration of ethical research, the research content, research activity design, feedback process for participants, possible harm or discomfort that may be experienced during the research, protection of privacy and information for participants, and freedom for participants to withdraw at any time were disclosed. All procedures, including the informed consent and the recruitment of participants, were reviewed and approved by the Research Ethics Office of National Taiwan University (NTU-REC).

Procedures: This study recruited students from two university-level badminton classes and performed 10week quasi-experimental teaching to the classes. Prior to the experiment, the researchers explained the research objective and procedures to the students and informed them that they are free to determine whether they wanted to participate in the experiment. The badminton skills test of [10] was administered to the two groups of students one week before introducing the experiment. These students were then grouped into high-performing, mediumperforming and low-performing groups using 33\% and $66 \%$ of the test score as critical values. The students were randomly assigned into an experimental group and a control group. The two groups receive teaching with identical content objectives. Before the experiment, the students completed a basic information form and signed an informed consent form, followed by participating in a pretest by filling out the Elective Motivation Scale of Physical Education Curriculum (EMSPEC). On the 11th week, the students filled out another EMSPEC form to complete the posttest. In order to ensure the interference of teacher's teaching behavior between the two groups, the teachers of the two groups conducted two focus meetings at the beginning of the experiment to determine the directions of the teaching materials of the experiment. Table 1 presents the course content.

Elective motivation scale of physical education curriculum (EMSPEC): The EMSPEC could access students' elective motivation in physical education curriculum. This EMSPEC scale took reference from 
Table 1. Course content.

\begin{tabular}{|c|c|c|c|c|}
\hline Teaching activities (SEM) & Stage & Week & Stage & Teaching activities (DI) \\
\hline $\begin{array}{l}\text { 1. Introduction to the history and rules } \\
\text { of badminton }\end{array}$ & \multirow{7}{*}{$\begin{array}{l}\text { Teaching } \\
\text { activities }\end{array}$} & 1 & \multirow{7}{*}{$\begin{array}{l}\text { Teaching } \\
\text { activities }\end{array}$} & 1. Introduction to the \\
\hline 2. Basic skills and game concept of & & 2 & & badminton \\
\hline badminton & & 3 & & 2. Basic skills and game \\
\hline 3. Heterogeneous grouping & & \multirow{4}{*}{4} & & concept of badminton \\
\hline 4. Discussion on game strategies and & & & & 3. Random grouping \\
\hline $\begin{array}{l}\text { team names, and the determination of } \\
\text { lineups }\end{array}$ & & & & $\begin{array}{l}\text { 4. Game strategy } \\
\text { description }\end{array}$ \\
\hline $\begin{array}{l}\text { 5. Planning of the preseason games and } \\
\text { refereeing practice }\end{array}$ & & & & 5. Referee work practice \\
\hline $\begin{array}{l}\text { 1. Comprehensive practice of basic } \\
\text { badminton skills }\end{array}$ & \multirow{4}{*}{ Preseason } & 5 & \multirow{4}{*}{$\begin{array}{l}\text { Teaching } \\
\text { activities }\end{array}$} & $\begin{array}{l}\text { 1.Comprehensive practice } \\
\text { of basic badminton skills }\end{array}$ \\
\hline $\begin{array}{l}\text { 2. Announcement of the preseason } \\
\text { schedule }\end{array}$ & & \multirow[t]{3}{*}{6} & & $\begin{array}{l}\text { 2.Learn about the rules of } \\
\text { the game }\end{array}$ \\
\hline $\begin{array}{l}\text { 3. Explanation on offense and defence } \\
\text { concepts }\end{array}$ & & & & $\begin{array}{l}\text { 3. Explanation on offense } \\
\text { and defence concepts }\end{array}$ \\
\hline 4. Preseason begins & & & & 4. Announce the schedule \\
\hline 1. Postseason (semifinals) & \multirow{2}{*}{ Postseason } & 8 & \multirow[b]{3}{*}{ competition } & 1.Group competition \\
\hline 2. Postseason (final) & & 9 & & 2. Game technology \\
\hline $\begin{array}{l}\text { 1. Award ceremony: The most } \\
\text { valuable player award and the best } \\
\text { sportspersonship award }\end{array}$ & $\begin{array}{l}\text { Celebration } \\
\text { Event }\end{array}$ & 10 & & $\begin{array}{l}\text { improvement instructions } \\
\text { 3. Announce the results of } \\
\text { the competition }\end{array}$ \\
\hline
\end{tabular}

the scales developed by [28] and comprised a total of 25 items (ex: I can learn skills and relevant knowledge from the elective physical education course; I will take elective physical education course again if there is a chance.). The scale showed acceptable fit $\left(\chi^{2}=571.86, p<0.05\right.$; RMSEA $=0.07, \mathrm{SRMR}=0.79, \mathrm{CFI}=0.95, \mathrm{GFI}=0.89, \mathrm{AGFI}=0.91$, $\mathrm{IFI}=0.95$, NNFI $=0.94$ ). The average variance extracted (AVE) of the latent variable was 0.80 , with a composite reliability (CR) of 0.95 . Thus, we concluded that the EMSPEC was psychometrically sound, with adequate reliability and validity.

Data analysis: To ensure that the two groups of students were taught with different teaching methods under identical conditions, a homogeneity test on the pretest scores of the two groups of students was performed. The independent variable was teaching method and the dependent variables was the EMSPEC. In this study, a $2 \times 3$ factorial design was applied; the two independent variables were teaching strategy (i.e., the SEM group vs. the DI group) and ability level (i.e., high ability level, medium ability level, and low ability level) and the one dependent variables was elective motivation of physical education curriculum. The Statistical Product and Service Solutions software package was employed to calculate the statistics with respect to data processing, and five analytical methods were applied to the results: 1 . Descriptive statistics were applied to analyze the distributions of the height, weight, and body mass index (BMI) of participants; 2. Chi-square testing was used to conduct a homogeneity test on the gender of participants; 3 . Independent-samples t testing was used to analyze the homogeneity of the height, weight, and BMI of participants; 4. Multivariate analysis of covariance (MANCOVA) was applied to compare and analyze the experimental and control groups in terms (i.e., teaching strategy and ability level) of EMSPEC posttest results after excluding the influence of pretest scores; and 5. Based on the standard proposed by [39], the Cohen's $\mathrm{d}$ effect size was divided into three levels: small $(0.2$ or lower), medium (0.5), and large ( 0.8 or higher); the $\eta 2$ (eta squared) was used for MANCOVA, and the thresholds were set to $\leq 0.02$ for small, 0.059 for medium, and $\geq 0.138$ for large. The significance levels for all statistical tests in this study were set to $\alpha<0.01$.

\section{Results}

Homogeneity test between the experimental and control group: The results for the demographic analyses indicated that there were no significant differences between the groups in terms of gender $\left(x^{2}=0.07, p>0.05\right.$, $\mathrm{d}=0.03)$, age $(\mathrm{t}=0.35, \mathrm{p}>0.05, \mathrm{~d}=0.07)$, height $(\mathrm{t}=0.03$, $\mathrm{p}>0.05, \mathrm{~d}=0.01)$, weight $(\mathrm{t}=1.45, \mathrm{p}>0.05, \mathrm{~d}=0.27)$, and body mass index $(\mathrm{t}=1.77, \mathrm{p}>0.05, \mathrm{~d}=0.33)$. That distributions the two groups were homogenous. Table 2 summarizes the demographic characteristics and physical fitness of the participants in the two groups.

Table 3 presents the results of homogeneity tests for the within-group regression coefficients of EMSPEC score. The regression line slope of EMSPEC score ( $F$ 
$\left.=2.08, \mathrm{p}=.15, \eta^{2}=.02\right)$ is identical. Thus, the pretest results do not differ from the posttest results because of differences in the treatment levels of the independent variables. The assumption of homogeneity of regression slopes is therefore met, and further covariance analyses were conducted.

Analysis results of elective motivation toward $\boldsymbol{P E}$ courses: As shown in Table 4, After the teaching intervention, the elective motivation of PE Curriculum scores of the students at the high, medium, and low ability levels in the experimental group were 3.38 (adjusted mean $=3.37), 3.31$ (adjusted mean $=3.34$ ), and 3.78 (adjusted mean $=3.81$ ), respectively; the scores of the students at the high, medium, and low ability levels in the control group were 3.33 (adjusted mean $=3.29$ ), 3.18 (adjusted mean $=3.19)$, and 3.23 (adjusted mean $=3.20)$, respectively.

Table 2. Demographic characteristics of the participants.

\begin{tabular}{lllll}
\hline Variable & $\begin{array}{l}\text { Experimental } \\
(\boldsymbol{n}=59 ; \boldsymbol{M}[S D])\end{array}$ & $\begin{array}{l}\text { Control } \\
(\mathbf{n}=56 ; \boldsymbol{M}[S D])\end{array}$ & $\begin{array}{l}\text { Total } \\
(\mathbf{n}=\mathbf{1 1 5} ; \boldsymbol{M}[S D])\end{array}$ & $\begin{array}{l}\text { Significance } \\
\text { (Effect Size) }\end{array}$ \\
\hline Gender & $32(\mathrm{M}): 27(\mathrm{~F})$ & $29(\mathrm{M}): 27(\mathrm{~F})$ & $61(\mathrm{M}): 54(\mathrm{~F})$ & $\mathrm{x}^{2}=0.07, \mathrm{p}>0.05(\mathrm{~d}=0.03)$ \\
Age & $21.42[0.75]$ & $21.38[0.73]$ & $21.40[0.74]$ & $\mathrm{t}=0.35, \mathrm{p}>0.05(\mathrm{~d}=0.07)$ \\
Height & $1.66[0.08]$ & $1.66[0.09]$ & $1.66[0.09]$ & $\mathrm{t}=0.03, \mathrm{p}>0.05(\mathrm{~d}=0.01)$ \\
Weight & $59.37[11.77]$ & $62.88[13.91]$ & $61.08[12.92]$ & $\mathrm{t}=1.45, \mathrm{p}>0.05(\mathrm{~d}=0.27)$ \\
BMI & $21.41[3.40]$ & $22.70[4.37]$ & $22.04[3.94]$ & $\mathrm{t}=1.77, \mathrm{p}>0.05(\mathrm{~d}=0.33)$ \\
\hline
\end{tabular}

Table 3. The homogeneity test with EMSPEC.

\begin{tabular}{llllllll}
\hline Source & Source & SS & df & MS & $\boldsymbol{F}$ & $\boldsymbol{p}$ & $\boldsymbol{\eta}^{\mathbf{2}}$ \\
\hline \multirow{2}{*}{ EMSPEC } & Group*pre-test & 0.16 & 1 & 0.16 & 2.08 & .15 & .02 \\
& Error & 8.29 & 111 & .08 & & & \\
\hline
\end{tabular}

Table 4. Descriptive statistics on elective motivation of PE curriculum of the experimental and control groups.

\begin{tabular}{|c|c|c|c|c|c|}
\hline & & \multicolumn{3}{|c|}{ B factor (Ability) } & \multirow{2}{*}{ Marginal Means } \\
\hline & & High & Medium & Low & \\
\hline \multirow{2}{*}{$\begin{array}{l}\text { A factor } \\
\text { (Group) }\end{array}$} & SEM & $3.37(3.38)$ & $3.34(3.31)$ & $3.81(3.78)$ & $3.49(3.51)$ \\
\hline & DI & $3.29(3.33)$ & $3.19(3.18)$ & $3.20(3.23)$ & $3.23(3.24)$ \\
\hline \multicolumn{2}{|c|}{ Marginal Means } & $3.33(3.35)$ & $3.27(3.24)$ & $3.51(3.51)$ & $3.37(3.37)$ \\
\hline
\end{tabular}

Table 5. Multivariate analysis of covariance for elective motivation of PE curriculum.

\begin{tabular}{lllllll}
\hline Source & SS & df & MS & F & Sig. & $\boldsymbol{\eta}^{2}$ \\
\hline Group (A) & 2.19 & 1 & 2.19 & $41.76^{*}$ & 0.00 & 0.28 \\
Ability(B) & 1.22 & 2 & 0.61 & $11.63^{*}$ & 0.00 & 0.18 \\
(A)X (B) & 1.53 & 2 & 0.77 & $14.66^{*}$ & 0.00 & 0.21 \\
Error & 5.65 & 108 & 0.52 & & & \\
Total & 1317.77 & 115 & & & & \\
\hline
\end{tabular}

Note: ${ }^{*} p<.01$ 
Table 6. Analysis of variance summary table (effects of group and ability on elective motivation of PE curriculum).

\begin{tabular}{lllllll}
\hline Source of variation & SS & DF & MS & F & sig & PC \\
\hline A factor (Group) & & & & & & \\
\hline B1(High) & 0.02 & 1 & 0.02 & 0.37 & 0.54 & \\
B2 (Medium) & 0.15 & 1 & 0.15 & 5.60 & 0.06 & \\
B3 (Low) & 3.05 & 1 & 3.05 & $30.66^{*}$ & 0.00 & SEM>DI \\
\hline B factor (Ability) & & & & & & \\
\hline A1 (SEM) & 2.64 & 2 & 1.32 & $15.58^{*}$ & 0.00 & Low> High \\
A2 (TP) & 0.21 & 2 & 0.10 & 2.69 & 0.08 & \\
\hline
\end{tabular}

Note: $* p<.01$.

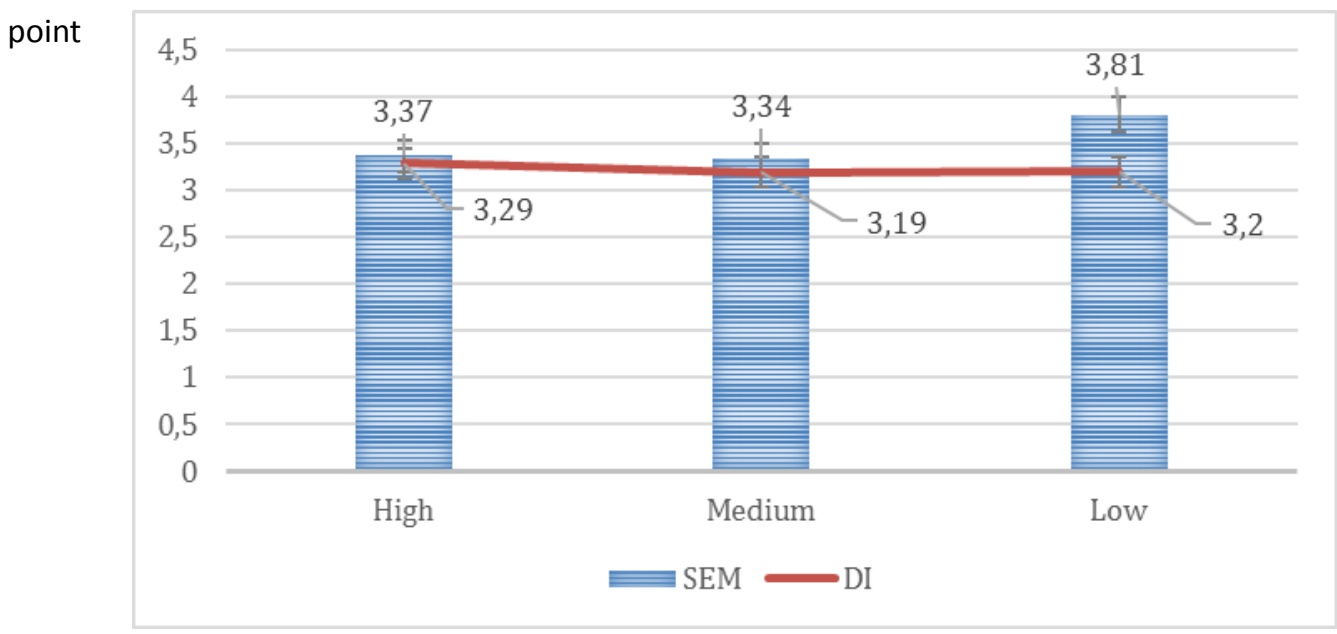

Fig. 1. Elective motivation performance between experiment group and control group.

\section{Discussion}

This study adopted a perspective based on the SEM to examine students' elective motivation toward PE courses and explored the effect of the SEM on the motivation of low-performing students to select PE courses. The results revealed that after the SEM was employed in PE, students' elective motivation toward PE courses improved significantly and was higher than that of students receiving DI. The SEM also effectively raised the elective motivation of low-performing students. Therefore, H1, $\mathrm{H} 2$ and $\mathrm{H} 3$ were validated, and the results concur with those of related studies [10, 15, 38, 40]. The inferences of this study were based on how the SEM can provide a game scenario in which students can demonstrate their skills. Moreover, such a scenario provides equal learning opportunities to all students and enables students to engage in interactive learning, thereby promoting peer imitation and allowing students to receive help and encouragement from peers. Accordingly, students can experience success in a teamwork setting, avoid a sense of loss and helplessness commonly experienced during competition-based learning, and change their elective motivation toward PE courses. The results of this study indirectly verified the discourse of several related studies $[15,16,41-43]$. The SEM can provide students with real sports experience. By playing different roles in a sports team, students can engage in a deeper level of learning and are more likely to exert great effort to learn. Accordingly, the team members can experience a sense of belonging and develop respect for one another. The SEM can also enhance students' engagement in sports while improving their motivation to select PE courses.

From a curriculum-based perspective, research on autonomous learning motivation and self-regulation has reported that motivation exerts a noticeable effect on learning processes and outcomes [44]. Motivation to exercise is highly correlated with exercise behavior and emotion (e.g., a sense of fulfilment, satisfaction, and enjoyment) [45]. In terms of the three basic psychological needs of SDT, autonomy needs reflect the desire of individuals to make their own choices about their activities (for instance: I choose physical education course because I like it, not because the university or my parents want me to take it). A sense of ability means that the individual feels competent in the environment (for instance: I believe that I can achieve the technical skills required by the teacher.) Relevance relates to the emotional relationship between individuals and the environment and other related parties (for instance: I feel that both the teacher and my peer students are very supportive when I take elective 
physical education classes). When the above three basic psychological needs are met, the individual's motivation for continuing taking the elective course is stimulated and strengthened.

Students' time spent at university is a critical period they can develop regular exercise habits, and this period exerts a substantial effect on students' regular exercise habits after they graduate [46]. If a student no longer exercises after graduation, it may be because he or she lacked a strong motivation to exercise while participating in PE classes [47]. The SEM emphasizes students' autonomous learning and their respect for differences between individuals. During sports learning, this model encourages all students to comprehensively participate in related activities and learn in an enjoyable environment. As a learner-oriented model, the SEM creates a learning environment that elicits the intrinsic motivation of students and allows them to experience a sense of autonomy. Therefore, the SEM can serve as a teaching model that supports and improves students' motivational needs [48]. Under this model, students experience a learning environment in a real-world context in which conventional game rules are adapted to students' learning needs, and students can engage in discussion and make decisions with their teammates according to the athletic ability of each of them and of their opponents [49]. Students enjoy education under the SEM because it bestows them with the autonomy to make game decisions and improves their teamwork and decision-making abilities [16]. Accordingly, teachers can implement the SEM in an adequate manner to help students attain course objectives and respond challenges appropriately.

From the perspective of student capability, a related study asserted that perceived competence, autonomy, and relatedness are innate psychological needs [27]. When sports participants satisfy these needs, their self-determination is improved; conversely, their selfdetermination is reduced [50]. In the SEM, the various roles of students and the celebration ceremony of the model help teachers examine students' individual differences. In addition to playing the role of players, students also learn to coach, referee, keep scores, and record each player's performance, which are all essential roles in a sports game. Under the premise of heterogeneous grouping, students of different abilities can assume roles that best fit their aptitudes, thereby allowing them to best demonstrate their capabilities. In addition, a celebration ceremony is hosted to present awards, making students feel that they are participating in a large event. According to the SEM concepts, other activities are also arranged, including the design of the team name, slogan, and flag, to integrate in-class activities with real-world group activities and create an enjoyable learning atmosphere. An analysis from the perspective of self-determination theory indicates that interest, as an intrinsic motivation, is a type of autonomous motivation that is positively correlated with learning behavior and emotion [26]. Autonomous motivation creates a virtuous circle for the learning engagement of university students, whereas low performance in a subject prompts student to avoid selecting courses related to the subject [51]. In summary, autonomous learning motivation is crucial to the learning process of university students, who tend to select courses on the basis of their interests [44].

The SEM is a student-centered teaching model in which the teacher gradually transfers power to students. Games are scheduled between teaching activities, and before the course is over, a ceremony is hosted to create an enjoyable team atmosphere. The entire learning process is recorded to raise students' interest in learning. The main form of learning in conventional narrative lectures involves receiving visual and auditory information. However, lowperforming students usually demonstrate more favorable learning outcomes through experiential learning. This type of learning not only increases such students' confidence and improves their interest in the subject but also provides them with more opportunities to participate in class activities according to their learning progress, allowing them to attain greater learning achievements. Moreover, employing a democratic and tolerant teaching approach to cultivating responsible, cultured, and passionate students is the fundamental component in the SEM [4, 5]. Adapting teaching strategies to the aptitudes of lowperforming students is highly conducive to the learning of such students. Through such a teaching approach, the motivation of low-performing students to select PE courses can be improved.

Overall, this quasi-experimental study verified the effectiveness of the SEM in improving the elective motivation of low-performing students toward PE courses. The study results provided evidence that the SEM raised low-performing students' motivation to select PE courses. The value of this study is that it provided valid evidence for PE instructors who are interested in using the SEM to improve elective motivation toward PE courses.

\section{Conclusion and recommendations}

In response to a growing awareness of the sustainable development of education worldwide, PE instructors tend to adopt innovative teaching strategies to design courses according to the needs and abilities of low-performing students, allowing such students to experience success in sport education. This study explored the effect of the SEM on the elective motivation of university students toward PE courses and supplemented the gaps in related research. The study results indicated that PE instructors can use the SEM to create effective course development strategies and improve the elective motivation of low-performing students. Therefore, this model holds considerable potential. The intervention employed in this study also provided strong evidence regarding the effect of the SEM on low-performing students. The findings may be applied to other PE activities to maximize students' motivation to select PE courses. However, this study only examined badminton classes in one university. Subsequent research is required to confirm the effectiveness of the SEM in facilitating the overall development of PE curricula. 


\section{Acknowledgments}

The corresponding author wants to thank Ming Chuan University (MCU, Taiwan) for supplying the necessary material for the execution of the work; and acknowledged all teachers and students who participated in this study. This work was supported by the MOE Teaching Practice Research, R.O.C.

\section{Funding}

This work was supported by the MOE Teaching Practice Research, R.O.C.

\section{Conflict of interest}

The authors declare no conflict of interest.

\section{References}

1. Wu CS, Wang LY. A study on analyzing the content of curriculum structure and improving general education of Universities in Taiwan. Curriculum \& Instruction Quarterly, 2017; 20: 1-23.

2. Tsangaridou N. Moving towards effective physical education teacher education for generalist primary teachers: A view from Cyprus. Education, 2016; 44: 632- 647. https://doi.org/10.1080/03004279.2014.952757

3. Kao CC. Development of team cohesion and sustained collaboration skills with the sport education model. Sustainability, 2019; 11: 23- 48. https://doi.org/10.3390/su11082348

4. Penney D, Clarke G, Quill M. Sport education in physical education: Research based practice. New York: Routledge; 2005. https://doi.org/10.4324/9780203497449

5. Penney D, Kinchin GD, Clarke G, Quill M. What is sport education and why is it timely to explore it? In: Penney D, Clarke G, Quill M, Kinchin D, editors. Sport and physical education: The key concepts. New York: Routledge; 2005. P. 3-22.

6. Huang WY. Laws/regulations and compulsory/elective course systems for physical education curriculum of University. Sports Research and Review, 2017; 140: 19-26.

7. Holt NL, Sehn ZL, Spence JC, Newton AS, Ball GDC. Physical education and sport programs at an inner city school: Exploring possibilities for positive youth development. Physical Education and Sport Pedagogy, 2012; 17: 97- 113. https://doi.org/10.1080/17408989.2010.548062

8. Mowling CM, Brock SJ, Eiler K, Rudisill M. Student motivation in physical education: breaking down barriers. Journal of Physical Education, Recreation \& Dance, 2004; 75: 40-45.

9. Zhang Y. Design and development of WEB-based remote network physical education teaching platform in colleges and universities. International Journal of Emerging Technologies in Learning, 2018; 13(4): 150- 161. https://doi.org/10.3991/ijet.v13i04.8478

10.Luo YJ. The influence of problem-based learning on learning effectiveness in students' of varying learning abilities within physical education. Innovations in Education and Teaching International, 2018; 56: 3- 13. https://doi.org/10.1080/14703297.2017.1389288

11.Hannon JC, Ratliff T. Cooperative learning physical education. Strategies, 2004; 17: 29- 32. https://doi.org/10.1080/08924562.2004.11000362

12.Parker MB, Curtner-Smith M. Health-related fitness in sport education and multi-activity teaching. Physical Education and Sport Pedagogy, 2005; 10: 1- 18. https://doi.org/10.1080/1740898042000334872

13.Kinchin GD. Sport Education: A View of the Research. Handbook of Physical Education, 1 Oliver's Yard, 55 City Road, London: EC1Y 1SP United Kingdom: SAGE Publications Ltd; 2006. P. 596-609. https://doi.org/10.4135/9781848608009.n33

14.Turan Z, Avinc Z, Kara K, Goktas Y. Gamification and education: Achievements, cognitive loads, and views of students. International Journal of Emerging Technologies in Learning, 2016; 11(7): 64-69. https://doi.org/10.3991/ijet.v11i07.5455

15.Pennington CG. Sport education and physical activity. International Journal of Physical Education, Fitness and Sports, 2019; 8: 122-125. https://doi.org/10.26524/ijpefs 19114

16.Siedentop D. Sport education: A retrospective. Journal of Teaching in Physical Education, 2002; 21: 409-418. https://doi.org/10.1123/jtpe.21.4.409

17.Perlman D. The influence of the sport education model on a motivated students' in-class physical activity. European Physical Education Review, 2012; 18: 335-345. https://doi.org/10.1177/1356336X12450795

18.Lund J, Tannehill D. Standards-based physical education curriculum development. Burlington (MA): Jones and Bartlett; 2014.

19.Pan YH. Teaching personal and social responsibility through sport education model. Quarterly of Chinese Physical Education, 2013; 27: 105-112.

20.O'Neil K, Krause JM. The sport education model: A track and field unit application. Journal of Physical Education, Recreation \& Dance, 2016; 87: 14-20. https://doi.org/10.1080/07303084.2016.1226217

21.Sinelnikov OA, Hastie PA. Student's autobiographical memory of participation in multiple sport education seasons. Journal of Teaching in Physical Education, 2010; 29: 167-183. https://doi.org/10.1123/jtpe.29.2.167

22. Wang WY, Chen YF, Chou LC. The effects of sport education model on students' volleyball skill performance and learning motivation. Journal of Exercise Health Research, 2015; 4: 39-47.

23. Wallhead T, Garn AC, Vidoni C, Youngberg C. Game play participation of a motivated students during sport education. Journal of Teaching in Physical Education, 2013; 32: 149-165. https://doi.org/10.1123/jtpe.32.2.149

24.DeciEL, Ryan RM.Intrinsicmotivationandself-determination in human behavior. New York: Plenum Press; 1985. https://doi.org/10.1007/978-1-4899-2271-7

25.Bang M, Wohn K, Shi C. The establishment of an e-learning system based on SDT. International Journal of Emerging Technologies in Learning, 2014; 9(4): 43-49. https://doi.org/10.3991/ijet.v9i4.3704

26.Ryan RM, Deci EL. Intrinsic and extrinsic motivations: classic definitions and new directions. Contemporary Educational Psychology, 2000; 25: 54-67. https://doi.org/10.1006/ceps.1999.1020

27.Benita M, Roth G, Deci EL. When are mastery goals more adaptive? It depends on experiences of autonomy support and autonomy.Journal of EducationalPsychology, 2014; 106:258. https://doi.org/10.1037/a0034007

28.Luo YJ, Chen WC, Kao CC, Ma IC. Constructing elective 
motivation scale of physical education curriculum with structural equation model. Journal of Sports AMOS Statistical and Applications, 2017; 6: 1-10.

29.Taylor IM, Ntoumanis N, Smith B. The social context as a determinant of teacher motivational strategies in physical education.PsychologyofSportandExercise,2009; 10:235-243. https://doi.org/10.1016/j.psychsport.2008.09.002

30.Dewey J. Democracy and education: An introduction to the philosophy of education. New York: The Macmillan Company; 1923.

31.Davis GA, Rimm SB. Education of the gifted and talented. Englewood Cliffs (NJ): Prentice Hall; 1989.

32.Williams KB. Academic support, social support, and professional development of higher and lower achieving psychology majors. North American Journal of Psychology, 2015; 17: 373-382.

33.VanZile-Tamsen C, Livingston JA. The differential impact of motivation on the self-regulated strategy use of high-and low achieving university students. Journal of University Student Development, 1999; 40: 54-60.

34.Landry JB, Sdmon MA. Self-determination theory as an organizing framework to investigate women's physical activity behavior. Quest, 2002; 54: 332-354. https://doi.org/10.1080/00336297.2002.10491782

35.Escriva-Boulley G, Tessier D, Ntoumanis N, Sarrazin P. Needsupportive professional development in elementary school physical education: Effects of a cluster-randomized control trial on teachers' motivating style and student physical activity. Sport,Exercise, andPerformancePsychology, 2018;7:218-34. https://doi.org/10.1037/spy0000119

36.Moreno-Murcia J, Huéscar Hernández E, Ruiz L. Perceptions of Controlling Teaching Behaviors and the Effects on the Motivation and Behavior of High School Physical Education Students. IJERPH 2018;15:2288. https://doi.org/10.3390/ijerph15102288.

37.Hills AP, Dengel DR, Lubans DR. Supporting public health priorities: Recommendations for physical education and physical activity promotion in schools. Progress in Cardiovascular Diseases, 2015; 57: 368-374. https://doi.org/10.1016/j.pcad.2014.09.010

38.Evans J. Equality, education, and physical education. London: Routledge; 2017.

39.Cohen J. Statistical Power Analysis for the Behavioral Sciences. 2nd ed. Routledge; 2013. https://doi.org/10.4324/9780203771587

40.Dana P, Peter C. Examining the influence of sport education on the precursors of a motivation. European Physical Education Review, 2016; 23: 212-222. https://doi.org/10.1177/1356336X16643921
41.Hastie PA, Buchanan AM. Teaching responsibility through sport education: prospects of a coalition. Research Quarterly for Exercise and Sport, 2000; 71: 25-35. https://doi.org/10.1080/02701367.2000.10608877

42.Pan Y-H, Huang C-H, Lee I-S, Hsu W-T. Comparison of Learning Effects of Merging TPSR Respectively with Sport Education and Traditional Teaching Model in High School Physical Education Classes. Sustainability, 2019;11:2057. https://doi.org/10.3390/su11072057

43.Rocamora I, González-Víllora S, Fernández-Río J, AriasPalencia NM. Physical activity levels, game performance and friendship goals using two different pedagogical models: Sport education and direct instruction. Physical Education \& Sport Pedagogy, 2019; 24: 87-102. https://doi.org/10.1080/17408989.2018.1561839

44.Zimmerman BJ, Schunk DH. Self-regulating intellectual processes and outcomes: a social cognitive perceptive. In: Dai DY, Sternberg RJ. Motivation, emotion and cognition: integrative perspectives on intellectual functioning and development. Mahnah (NJ): Lawrence Erlbaum Associates; 2004. P. 323-349.

45.Treasure DC, Robert GC. Students' perceptions of the motivational climate, achievement beliefs, and satisfaction in physical education. Research Quarterly for Exercise and Sport, 2001; 72: 165-175. https://doi.org/10.1080/02701367.2001.10608946

46.Savage MP. University student' motivation for participation in a basic instruction program. College Student Journal, 1998; 32: 58-65.

47.Biddle SJH, Mutrie N. Psychology of physical activity determinants, well-being and intervention. London; New York: Routledge; 2001.

48.Perlman D. Motivating the student: Sport education can be a framework for success. Journal of Physical Education, Recreation \& Dance, 2014; 85: 12-16. https://doi.org/10.1080/07303084.2014.926845

49.Chow JY. Nonlinear learning underpinning pedagogy: Evidence, challenges, and implications. Quest, 2013; 65: 469-484. https://doi.org/10.1080/00336297.2013.807746

50.Vallerand RJ, Rousseau FL. Intrinsic and extrinsic motivation in sport and exercise: A review using the hierarchical model of intrinsic and extrinsic motivation. In: Singer RN, Hausenblas HA, Janelle CM, ediros. Handbook of sport psychology. 2nd ed. New York: Wiley; 2001. P. 389-416.

51.Lee YM, Sun SH. The relationship between autonomous motivation of course-taking and learning engagement on college students. Journal of Research in Education Sciences, 2010; 55: 155-182. 


\section{Information about the authors:}

Chun-Chieh Kao; Corresponding author); http://orcid.org/0000-0002-1715-9793; kao@mail.mcu.edu.tw; Office of Physical Education, Ming Chuan University ; 5 De Ming Rd., Gui Shan District, Taoyuan City 333, Taiwan (R.O.C.).

Yu-Jy Luo; http://orcid.org/0000-0002-8771-3083; anitaluo@mail.mcu.edu.tw; Office of Physical Education, Ming Chuan University ; 5 De Ming Rd., Gui Shan District, Taoyuan City 333, Taiwan (R.O.C.).

\section{Cite this article as:}

Chun-Chieh Kao, Yu-Jy Luo. The influence of low-performing students' motivation on selecting courses from the perspective of the sport education model. Physical education of students, 2019;23(6):269-278.

https://doi.org/10.15561/20755279.2019.0601

This is an Open Access article distributed under the terms of the Creative Commons Attribution License, which permits unrestricted use, distribution, and reproduction in any medium, provided the original work is properly cited http://creativecommons.org/licenses/by/4.0/deed.en

Received: 26.10 .2019

Accepted: 23.11.2019; Published: 18.12.2019 